\title{
Immunologically reactive $M$. leprae antigens with relevance to diagnosis and vaccine development
}

\author{
Lucas H Sampaio ${ }^{1}$, Mariane MA Stefani ${ }^{1 *}$, Regiane M Oliveira', Ana LM Sousa', Greg C Ireton², Steven G Reed²,
} Malcolm S Duthie ${ }^{2}$

\begin{abstract}
Background: Leprosy is a chronic infectious disease caused by Mycobacterium leprae that can manifest a wide variety of immunological and clinical outcomes ranging from potent humoral responses among borderline lepromatous (BL) and lepromatous (LL) patients to strong cellular responses among tuberculoid (TT) and borderline tuberculoid (BT) patients. Until recently, relatively little has been known about the immune responses to individual proteins of $M$. leprae recognized during leprosy.

Methods: The immune reactivity to a panel of $33 \mathrm{M}$. leprae recombinant proteins was evaluated among leprosy patients and controls from a high endemic area for leprosy (Goiania/GO, Central Brazil). Serum IgG responses were measured by ELISA (45 participants/group) and T cell responses (20 participants/group) were evaluated by IFNgamma production in 24 hours whole blood cultures with antigen (whole blood assay-WBA). Study groups were newly diagnosed, untreated TT/BT and BL/LL leprosy patients classified by Ridley Jopling criteria and household contacts of BL/LL patients (HHC). Control groups were HIV-1 negative pulmonary tuberculosis patients (TB) and healthy individuals from the same endemic area (EC). In silico predictions indicated the level of identity of M. leprae proteins with homologues in other mycobacteria and the presence of T cell and B cell epitopes.

Results: Despite the prediction that all proteins would be reactive, 16 of 33 (48\%) of the single proteins tested were immunogenic (recognized in WBA or ELISA) and seventeen were non-immunogenic (not recognized in either assay). Among the 16 immunogenic proteins, 9 were considered leprosy specific in WBA inducing cell-mediated IFN-gamma secretion from TT/BT patients and HHC. Three of these proteins were also leprosy specific in serology being recognized by serum IgG from LL/BL patients. Seven of the immunogenic proteins were not leprosy specific.

Conclusions: New M. leprae antigens recognized by antibody responses of BL/LL patients and cellular responses of TT/BT leprosy patients were identified. An improved serological diagnostic test for leprosy could be developed by incorporating these IgG-reactive antigens to the current PGL-I based tests. Moreover our data indicate that the WBA is a robust, relatively simple and user friendly format for a T cell based diagnostic test. The field use of these test formats in leprosy endemic countries could contribute to early leprosy diagnosis before the development of deformities and disabilities.
\end{abstract}

\section{Background}

Leprosy, caused by infection with Mycobacterium leprae, is one of the oldest known human infectious diseases and remains an important public health problem for many countries, including Brazil [1]. M. leprae infects macrophages and Schwann cells, causing peripheral nerve

\footnotetext{
* Correspondence: mstefani@iptsp.ufg.br

${ }^{1}$ Tropical Pathology and Public Health Institute, Federal University of Goiás, Rua 235 esquina com 1a Avenida, Setor Universitário, sala 335, Goiânia, GO, 74605050, Brazil

Full list of author information is available at the end of the article
}

damage which results in sensory and motor loss that ultimately cause the severe disability that is a hallmark of leprosy [2]. Leprosy actually manifests across a bacteriologic, clinical, immunologic and pathologic spectrum that allows classification into five forms according to the Ridley-Jopling scale. Weak antibody responses and strong cell-mediated immunity (CMI) classically characterize the immune response of tuberculoid (TT) and borderline tuberculoid (BT) patients who have a low bacterial burden. In contrast, strong antibody responses and weak CMI are classically observed in borderline borderline (BB),

\section{Biomed Central}


borderline lepromatous (BL) and lepromatous (LL) cases that have a high bacterial burden and are believed to transmit $M$. leprae infection [3-5].

Seeking to eliminate leprosy by the year 2000, a campaign by the World Health Organization was based on widespread provision and use of multidrug therapy (MDT) to control infection and reduce transmission. This campaign has produced a large decline in global prevalence of leprosy over the last 20 years, but despite this, the new case detection rate is still high in many regions [1]. The diagnosis of leprosy remains based on the appearance of clinically relevant manifestations and treatment has been simplified to incorporate recommended MDT regimen of 6 months for paucibacillary patients ( $\mathrm{PB}$; encompassing $\mathrm{TT}$ and $\mathrm{BT}$ forms) and of 12 months for multibacillary patients (MB; encompassing $\mathrm{LL}, \mathrm{BL}, \mathrm{BB}$ and some BT forms). Unfortunately, the scarcity of early signs or symptoms, as well as the problem that leprosy symptoms may be confused with other diseases, often leads to significant delays in proper diagnosis and appropriate treatment [6]. A further compounding factor is the reduction in the number of clinicians with expertise at identifying leprosy that has occurred alongside the reduction in case numbers [7]. Early leprosy diagnosis, to promote even earlier treatment, is regarded as critical to provide further reductions in transmission and decrease the number of patients presenting with disabilities $[8,9]$. To date, simple, rapid tests have been developed to diagnose MB leprosy but tests for $\mathrm{PB}$ leprosy are not yet available $[10,11]$.

As with other diseases, rapid and objective diagnosis of leprosy could be achieved by the recognition of disease-specific immune responses [8]. Due to the dichotomous nature of immune responses of leprosy patients, diagnostic tests for all leprosy forms would probably require antigens that are targets of both antibody and cellular responses $[8,12]$. The identification of $\mathrm{T}$ cellreactive antigens may also reveal proteins that are part of the protective response against leprosy that are worthy of further examination in the context of vaccine development. The selection and production of proteins for immune evaluation has been expedited by recent advances such as the sequencing of the M. leprae genome and could be further simplified when coupled with effective in silico epitope predictions [13-18]. Most studies investigating the reactivity of $M$. leprae antigens have described either the antibody or $\mathrm{T}$ cell reactivity among leprosy patients but have not typically compared these responses in parallel $[4,9,19-26]$. The current study was designed to explore the immune reactivity of a panel of $33 \mathrm{M}$. leprae recombinant proteins among leprosy patients and to concomitantly evaluate the utility of computational softwares to predict this reactivity. This study identified several antigens that are targets of the cellular response and some that are targets of the antibody response. Moreover it indicated that the benefits of current computational predictions of immune reactivity were limited.

\section{Methods}

\section{Study participants}

This study was approved by local (Comitê de Ética em Pesquisa Humana e Animal do Hospital das Clínicas da Universidade Federal de Goias) and National Ethics Commission (Comissão Nacional de Ética Pesquisa/ CONEP/Brazil protocols \#4862 and \#12962). Newly diagnosed, previously untreated leprosy patients were recruited between November 2006 and January 2009 at a main outpatient clinic (Centro de Referência em Diagnóstico e Terapêutica) in Goiânia, Goiás State, in Central-West Brazil. Before recruitment all patients were provided complete dermato-neurological evaluations by a dermatologist with expertise in leprosy diagnosis. Participants were included only after signing written informed consent forms. Patients were assigned to leprosy groups based upon their immediate diagnosis, and were subsequently thoroughly characterized according to Ridley-Jopling criteria, taking into account clinical, bacilloscopic and histopathological findings [27]. All patients assigned to the TT/BT group had negative bacilloscopic index (BI), whereas LL/BL cases were BI positive. Tuberculosis patients (TB), healthy household contacts of LL/BL patients (HHC) and healthy endemic controls (EC) from the same endemic region were included as control groups. TB patients were HIVnegative individuals with clinically confirmed pulmonary tuberculosis (Mycobacterium tuberculosis sputumpositive) in their final 3 months of chemotherapy. HHC were adults living in the same house as a multibacillary index case for at least 6 months prior to study enrollment and blood collection. EC were healthy individuals recruited among non leprosy patients at a public health center from the same endemic setting. EC had neither tuberculosis nor history of leprosy in their families. All study participants had a BCG scar, consistent with the neonatal BCG vaccination coverage close to $100 \%$ in this recruitment setting. All study participants came from Goias State, an endemic region for leprosy (prevalence rate $=6.02$ patients $/ 10000$ inhabitants). The serology study included 45 participants per group and the $\mathrm{T}$ cell study included 20 participants per group and results from these separate studies were combined in this manuscript. The fine composition of each study group is summarized in Table 1.

\section{Antigens}

Thirty-three $M$. leprae recombinant proteins were evaluated for immune reactivity (ML0022, ML0051, ML0098, 
Table 1 Main characteristics of study groups and anti PGL-I serology data.

\begin{tabular}{ccccc}
\hline Group & Sex ratio $(\mathbf{m} / \mathbf{f})$ & Mean age (years, range) & BI (mean, range) & PGL-I serology mean OD (range) \\
\hline PB (29 TT/36 BT) & $31 / 34$ & $33(18-76)$ & $0(0)$ & $0,19(0-1,03)$ \\
MB (23 BL/42 LL) & $37 / 28$ & $51(18-100)$ & $3.75(0.5-6.0)$ & $0,82(0,08-2,76)$ \\
HHC & $32 / 33$ & $36(19-60)$ & na & $0,09(0-0,53)$ \\
TB & $39 / 26$ & $38(20-67)$ & na & $0,07(0-0,30)$ \\
EC & $32 / 33$ & $35(18-58)$ & na & $0,07(0,01-0,30)$ \\
\hline
\end{tabular}

PB: paucibacillary leprosy consisting of $\mathrm{T}$ and BT forms; MB: multibacillary leprosy consisting of BL and LL forms; $\mathrm{m} / \mathrm{f}$ : male/female ratio; BI- bacilloscopic index; Optical density (OD) of IgM antibodies to PGL-I antigen detected by ELISA; na: not applicable.

ML0176, ML0276, ML0393, ML0405, ML0489, ML0491, ML0540, ML0810, ML0811, ML0840, ML1383, ML1556, ML1632, ML1181, ML1481, ML1633, ML1685, ML2028, ML2044, ML2055, ML2203, ML2331, ML2346, ML2358, ML2380, ML2541, ML2603, ML2629, ML2655 and ML2659). Proteins were selected either from previous $M$. leprae cDNA library screening results [28] or on the basis of homology with known secreted M. tuberculosis proteins. Cloning and purification from E. coli were performed as previously described [4,28]. Endotoxin levels for each protein were $<100 \mathrm{EU} / \mathrm{mg}$ protein, as measured by Limulus Amebocyte Lysate QCL-1000 assay (Lonza Inc., Basel, Switzerland). Details for selected $M$. leprae recombinant proteins are provided in Table 2.

\section{CMI determination by whole blood assay (WBA)}

WBA was performed as previously described [4]. Briefly, at the time of initial diagnosis and operational assignment to $\mathrm{MB}$ or $\mathrm{PB}$ groups, prior to full characterization by Ridley-Jopling, undiluted heparinized venous whole blood (Greiner) was collected. Whole blood was plated into 24-well plates (450 $\mu \mathrm{l} /$ well; Sigma, St. Louis, MO) within 2 hours of collection and incubated with stimulants for 24 hours at $37^{\circ} \mathrm{C} 5 \% \mathrm{CO}_{2}$. Each assay included stimulation with $10 \mu \mathrm{g} / \mathrm{ml}$ of individual $M$. leprae recombinant protein for experimental evaluations, and with PBS alone, $10 \mu \mathrm{g} / \mathrm{ml} M$. leprae cell sonicate (MLCS; provided by Dr. John Spencer, Colorado State University, Fort Collins, CO under NIH contract N01 AI-25469) or $1 \mu \mathrm{g} / \mathrm{ml}$ PHA (Sigma) as controls (Additional File 1). Approximately $150 \mu \mathrm{l}$ plasma were collected and stored at $-20^{\circ} \mathrm{C}$ until IFN $\gamma$ determination. IFN $\gamma$ concentration was determined by ELISA, according to the manufacturer's instructions (eBioscience kit, San Diego, CA). The IFN $\gamma$ ELISA employed had a detection limit of $20 \mathrm{pg} / \mathrm{ml}$ and an arbitrary cut-off point of $50 \mathrm{pg} / \mathrm{ml}$ was used to determine positive responses.

\section{Antibody ELISA to $M$. leprae recombinant proteins}

Serum IgG antibodies were determined by ELISA as previously described [3]. Polysorp 96-well plates (Nunc, Rochester, NY) were coated with $2 \mu \mathrm{g} / \mathrm{ml}$ recombinant protein at $4{ }^{\circ} \mathrm{C}$ and blocked with $\mathrm{PBS} /$ Tween-20 with $1 \%$ (wt/vol) BSA. Serum samples diluted $1 / 200$ in $0.1 \%$ BSA were added and incubated for 1 hour at RT. Plates were washed and incubated with horseradish peroxidaseconjugated anti-human IgG (Southern Biotech, Birmingham, AL). After washing, reactions were developed with peroxidase color substrate (KPL, Gaithersburg, MD), and quenched by the addition of $1 \mathrm{~N} \mathrm{H}_{2} \mathrm{SO}_{4}$. The corrected optical density of each well at $450 \mathrm{~nm}$ was read using a VERSAmax microplate reader (Molecular Devices, Orleans Drive Sunnyvale, CA). Responses were defined as positive if the median was above the arbitrary cut-off (OD >0.3).

\section{ELISA to PGL-I antigen}

IgM antibodies to $M$. leprae cell wall phenolic glycolipid I (PGL-I) were detected as described [3]. Briefly $200 \mathrm{ng} /$ $\mathrm{ml}$ of natural disaccharide with octyl linkage (NDO) conjugated to bovine serum albumin (NDO-BSA; kindly supplied by John Spencer, Colorado State University, under NIH contract N01 AI-25469) was used. Serum samples diluted $1 / 300$ in $0.1 \%$ BSA were tested in duplicates. After incubation and washings horseradish peroxidase-conjugated to anti human IgM (Rockland Immunochemicals, Gilbertsville, PA) was added and incubated. After washings peroxidase color substrate (KPL, Gaithersburg, MD) was added and the reaction was quenched by the addition of $1 \mathrm{~N} \mathrm{H} 2 \mathrm{SO} 4$. The optical density (OD) was read at $450 \mathrm{~nm}$. Positive responses were defined as an OD of $2 x$ the mean OD of healthy endemic controls. Results of IgM anti PGL-I serology in each study group are shown in Table 1.

\section{Comparative genomics and epitope predictions}

The amino acid sequences of the $M$. leprae proteins evaluated in this study were obtained from the Leproma website (available at http://genolist.pasteur.fr/Leproma/) and the SANGER CDS Retrieve Information (available at http://www.sanger.ac.uk/cgi-bin/yeastpub/get_cds?orga nism=M_leprae) $[14,16]$. The percentage of amino acid identity of each $M$. leprae protein tested was assessed against homologues in other mycobacteria that were revealed by the comparative protein analyses based on complete proteome databases from other mycobacteria that have the potential to infect humans: M. tuberculosis, 
Table 2 Representative $M$. leprae recombinant antigens examined by comparative genomics and actual immune responses.

\begin{tabular}{|c|c|c|c|c|c|c|c|c|c|c|c|}
\hline \multirow[b]{2}{*}{ Gene } & \multirow[b]{2}{*}{ Predicted Function } & \multirow[b]{2}{*}{$\begin{array}{l}\text { Size } \\
\text { (aa) }\end{array}$} & $\%$ Ami & no acid ident & tity and ortho & \multirow[b]{2}{*}{ M. marinum } & \multirow[b]{2}{*}{$\begin{array}{c}M . \\
\text { tuberculosis }\end{array}$} & \multicolumn{2}{|c|}{$\begin{array}{l}\text { Number } \\
\text { of } \\
\text { Predicted } \\
\text { epitopes }^{2}\end{array}$} & \multicolumn{2}{|c|}{$\frac{\text { Immunogenicity }}{\text { specificity }^{3}}$} \\
\hline & & & $\begin{array}{c}M . \\
\text { ulcerans }\end{array}$ & M. avium & $\begin{array}{l}\text { M. bovis } \\
\text { (BCG) }\end{array}$ & & & $\begin{array}{c}\mathrm{T} \\
\text { cell }\end{array}$ & $\begin{array}{l}\mathrm{B} \\
\text { cell }\end{array}$ & WBA IFN $\gamma$ & $A b$ \\
\hline ML0405 & hypothetical protein & 394 & $\begin{array}{c}29 \\
\text { (MUL_5045) }\end{array}$ & - & $\begin{array}{c}62 \\
\text { (BCG_3680C) }\end{array}$ & $\begin{array}{c}57 \\
\text { (MMAR_4515) }\end{array}$ & $\begin{array}{c}62 \\
\text { (Rv3616c) }\end{array}$ & 7 & 39 & $+/+$ & $+/+$ \\
\hline ML2331 & possible secreted protein & 256 & $\begin{array}{c}81 \\
\left(M U L \_4308\right)\end{array}$ & $\begin{array}{c}80 \\
\text { (MAV_0385) }\end{array}$ & $\begin{array}{c}82 \\
\left(B C G \_3777\right)\end{array}$ & $\begin{array}{c}81 \\
\text { (MMAR_5233) }\end{array}$ & 81 (Rv3717) & 4 & 24 & $+/+$ & $+/+$ \\
\hline ML2055 & $\begin{array}{l}\text { fibronectin attachment } \\
\text { protein }\end{array}$ & 287 & $\begin{array}{c}65 \\
\text { (MUL_3017) }\end{array}$ & $\begin{array}{c}57 \\
\left(M A V \_2859\right)\end{array}$ & $\begin{array}{c}67 \\
\left(B C G \_1896\right)\end{array}$ & $\begin{array}{c}65 \\
\text { (MMAR_2737) }\end{array}$ & 67(Rv1860) & 6 & 15 & $+/+$ & $+/+$ \\
\hline ML1685 & $\begin{array}{l}\text { 3-isopropylmalate } \\
\text { dehydratase }\end{array}$ & 476 & $\begin{array}{c}86 \\
\text { (MUL_1968) }\end{array}$ & $\begin{array}{c}88 \\
\text { (MAV_3838) }\end{array}$ & $\begin{array}{c}88 \\
\text { (BCG_3009C) }\end{array}$ & $\begin{array}{c}88 \\
\text { (MMAR_1726) }\end{array}$ & $\begin{array}{c}88 \\
\text { (Rv2988c) }\end{array}$ & 3 & 25 & $+/+$ & - \\
\hline ML1632 & possible hydrolase & 511 & $\begin{array}{c}73 \\
\left(M U L \_1334\right)\end{array}$ & $\begin{array}{c}77 \\
\left(M A V \_2243\right)\end{array}$ & $\begin{array}{c}75 \\
\text { (BCG_2040C) }\end{array}$ & $\begin{array}{c}74 \\
\text { (MMAR_3295) }\end{array}$ & $\begin{array}{c}75 \\
\text { (Rv2223c) }\end{array}$ & 4 & 32 & $+/+$ & - \\
\hline ML1556 & initiation factor IF-2 & 924 & $\begin{array}{c}83 \\
\text { (MUL_2122) }\end{array}$ & $\begin{array}{c}81 \\
\text { (MAV_3693) }\end{array}$ & $\begin{array}{c}83 \\
\text { (BCG_2859C) }\end{array}$ & $\begin{array}{c}82 \\
\text { (MMAR_1894) }\end{array}$ & $\begin{array}{c}83 \\
\text { (Rv2839c) }\end{array}$ & 3 & 17 & $+/+$ & - \\
\hline ML2044 & $\begin{array}{l}\text { Possible glycosyl hydrolase } \\
\text { (pseudogene) }\end{array}$ & 73 & - & - & - & - & - & 3 & 7 & $+/+$ & - \\
\hline ML0840 & hypothetical protein & 434 & - & $\begin{array}{c}66 \\
\left(M A V_{-} 2053\right)\end{array}$ & - & - & - & 3 & 22 & $+/+$ & - \\
\hline ML0276 & hypothetical protein & 147 & - & $\begin{array}{c}71 \\
\left(M A V_{-} 4774\right)\end{array}$ & $\begin{array}{c}78 \\
\left(B C G \_0427\right)\end{array}$ & $\begin{array}{c}70 \\
\text { (MMAR_0687) }\end{array}$ & 78 (Rv0390) & 5 & 14 & $+/+$ & $+/-$ \\
\hline ML2541 & $\begin{array}{l}\text { acyl-CoA synthase } \\
\text { (pseudogene) }\end{array}$ & 146 & $\begin{array}{c}77 \\
\text { (MUL_0004) }\end{array}$ & $\begin{array}{c}78 \\
\left(M^{\prime} V_{-} 0004\right)\end{array}$ & $\begin{array}{c}83 \\
\left(B C G \_0004\right)\end{array}$ & $\begin{array}{c}78 \\
\text { (MMAR_0004) }\end{array}$ & 77 (Rv0004) & 5 & 15 & $+/-$ & - \\
\hline ML2203 & hypothetical protein & 373 & $\begin{array}{c}76 \\
\text { (MUL_0420) }\end{array}$ & $\begin{array}{c}76 \\
\left(\mathrm{MAV} \_0750\right)\end{array}$ & $\begin{array}{c}77 \\
\text { (BCG_0863C) }\end{array}$ & $\begin{array}{c}75 \\
\text { (MMAR_4878) }\end{array}$ & $\begin{array}{c}77 \\
\text { (Rv0811c) }\end{array}$ & 6 & 17 & $+/-$ & - \\
\hline ML2358 & probable acyl-CoA synthase & 583 & $\begin{array}{c}77 \\
\text { (MUL_2020) }\end{array}$ & $\begin{array}{c}56 \\
\left(M_{1} V_{-} 1328\right)\end{array}$ & $\begin{array}{c}77 \\
\left(B C G \_2952\right)\end{array}$ & $\begin{array}{c}77 \\
\text { (MMAR_1777) }\end{array}$ & 76 (Rv2930), & 3 & 15 & $+/-$ & - \\
\hline ML2346 & hypothetical protein & 301 & - & - & - & - & - & 5 & 12 & $+/-$ & - \\
\hline ML2380 & possible secreted protein & 153 & $\begin{array}{c}65 \\
\text { (MUL_1413) }\end{array}$ & $\begin{array}{c}66 \\
\text { (MAV_4695) }\end{array}$ & $\begin{array}{c}66 \\
\text { (BCG_0494C) }\end{array}$ & $\begin{array}{c}65 \\
\text { (MMAR_0777) }\end{array}$ & $\begin{array}{c}66 \\
\text { (Rv0455c) }\end{array}$ & 3 & 15 & $+/-$ & - \\
\hline ML2603 & possible lysophospholipase & 279 & $\begin{array}{c}73 \\
\text { (MUL_1077) }\end{array}$ & $\begin{array}{c}77 \\
\left(M A V \_4997\right)\end{array}$ & $\begin{array}{c}74 \\
\left(B C G \_0220\right)\end{array}$ & $\begin{array}{c}74 \\
\text { (MMAR_0427) }\end{array}$ & 74 (Rv0183) & 5 & 16 & $+/-$ & - \\
\hline ML0022 & hypothetical protein & 488 & $\begin{array}{c}71 \\
\text { (MUL_0024) }\end{array}$ & $\begin{array}{c}66 \\
\left(M A V \_0024\right)\end{array}$ & $\begin{array}{c}72 \\
\text { (BCG_0050c) }\end{array}$ & $\begin{array}{c}69 \\
\text { (MMAR_0022) }\end{array}$ & 72 (Rv0020) & 5 & 17 & $+/-$ & - \\
\hline
\end{tabular}

${ }^{1}$ Blast Search for amino acid identity was performed using BLAST Uniprot (http://www.uniprot.org/). $(-)=$ no homologue found. Locus_tag othologous genes are indicated within parentheses.

2 Promiscuous T cell epitopes predicted to be recognized by least 26 of 51 different HLA-DR alleles identified by PROPED server (http://www.imtech.res.in/ raghava/propred/), and the number of potential B cell epitopes predicted by ABCpred server (http://www.imtech.res.in/raghava/abcpred/ABC_submission.html). ${ }^{3} \mathrm{Immu} / \mathrm{spec}=$ immunogenicity/specificity; WBA $+/+=$ immunogenic protein that gives specific cellular response; WBA $+/-=$ immunogenic protein that gives unspecific cellular response; $A b+/+$ : immunogenic protein that induces specific antibody response; Ab+/-: immunogenic protein that induces unspecific antibody response. $(-)=$ not immunogenic

Mycobacterium avium, Mycobacterium smegmatis, Mycobacterium marinum, Mycobacterium ulcerans, Mycobacterium bovis BCG, Mycobacterium paratuberculosis and Mycobacterium microti. BLAST UniProt (The Universal Protein Resource) database (available at http://www. uniprot.org) was used to compare a given amino acid sequence with sequences of other proteins from the NCBI database indicating sequences with identity above $30 \%$ $[15,29]$. The potential of the selected $M$. leprae proteins to present promiscuous MHC class II T cell epitopes was predicted by PROPRED server (available at http://www. imtech.res.in/raghava/propred/) which uses a panel of 51 different HLA-DR alleles (HLA-DRB1 and HLA-DRB5) $[13,30]$. The prediction of $B$ cell epitopes containing 16 amino acids in the selected $M$. leprae proteins was attained using the artificial neural network based server ABCpred (available at http://www.imtech.res.in/raghava/ abcpred/ABC_submission.html) [17,31].

\section{Statistical analysis}

Exploratory data analysis, including box-plots and scatter plots, medians and interquartile range (IQR) were used to analyze the IFN $\gamma$ levels and OD of IgG reactivity among different study and control groups. Proteins that 
demonstrated reactivity above the arbitrary cut off (OD $>0.3$ for IgG ELISA or IFN $\gamma$ secretion $>50 \mathrm{pg} / \mathrm{ml}$ in WBA) were classified as "immunogenic". For T cell recognition $M$. leprae-specificity was defined according to reactivity of proteins among TT/BT leprosy patients and at risk HHC, and lack of reactivity among TB and EC groups. For serology $M$. leprae specific proteins were recognized by IgG antibodies from leprosy patients especially BL/LL categories and by lack of recognition by HHC, EC and TB groups. Statistical significance was assessed by Kruskall-Wallis one way analysis of variance for comparison of multiple groups and Mann-Whitney for comparison between two groups. Results were considered statistically significant when $p$-values $<0.05$ were obtained.

\section{Results}

ML0405, ML2055 and ML2331 proteins elicit leprosyspecific cellular and humoral responses

Dependent upon their disease presentation, leprosy patients can be characterized as having strong antibody responses $(\mathrm{MB} ; \mathrm{LL} / \mathrm{BL})$ or strong cellular responses $(\mathrm{PB}$; TT/BT) against crude $M$. leprae antigens. It is unclear if these different patient groups respond to the same or different individual antigens. To address this question, we compared the antigen-specific immune response of leprosy patients and controls. When incubated with blood from TT/BT and HHC groups, the ML0405, ML2055 and ML2331 proteins induced strong IFN $\gamma$ production (Figure 1). The ML0405 and ML2055 antigens each induced secretion of IFN $\gamma$ greater than $50 \mathrm{pg} / \mathrm{ml}$ in 95\% (19 of 20) of TT/BT leprosy patients examined. The ML2331 antigen induced response greater than $50 \mathrm{pg} / \mathrm{ml}$ IFN $\gamma$ in $85 \%$ (17 of 20 ) of the TT/BT cases examined. The ML0405 and ML2331 proteins also induced production of IFN $\gamma$ levels above the $50 \mathrm{pg} / \mathrm{ml}$ cut-off among $80 \%$ HHC (16 of 20 cases to each antigen), consistent with this group being exposed to M. leprae. The ML2055 antigen similarly induced secretion of IFN $\gamma$ greater than $50 \mathrm{pg} / \mathrm{ml}$ in $75 \% \mathrm{HHC}$ ( 15 of 20 cases). In contrast, with the exception of one $\mathrm{LL} / \mathrm{BL}$ patient responding to ML0405 and one EC responding to ML2055, IFN $\gamma$ responses above $50 \mathrm{pg} / \mathrm{ml}$ were not observed in the LL/BL leprosy or control groups (Figure 1).

Although not recognized in terms of IFN $\gamma$ production within WBA with LL/BL blood, as we previously reported, the ML0405 and ML2331 proteins were well recognized by serum IgG from LL/BL leprosy group

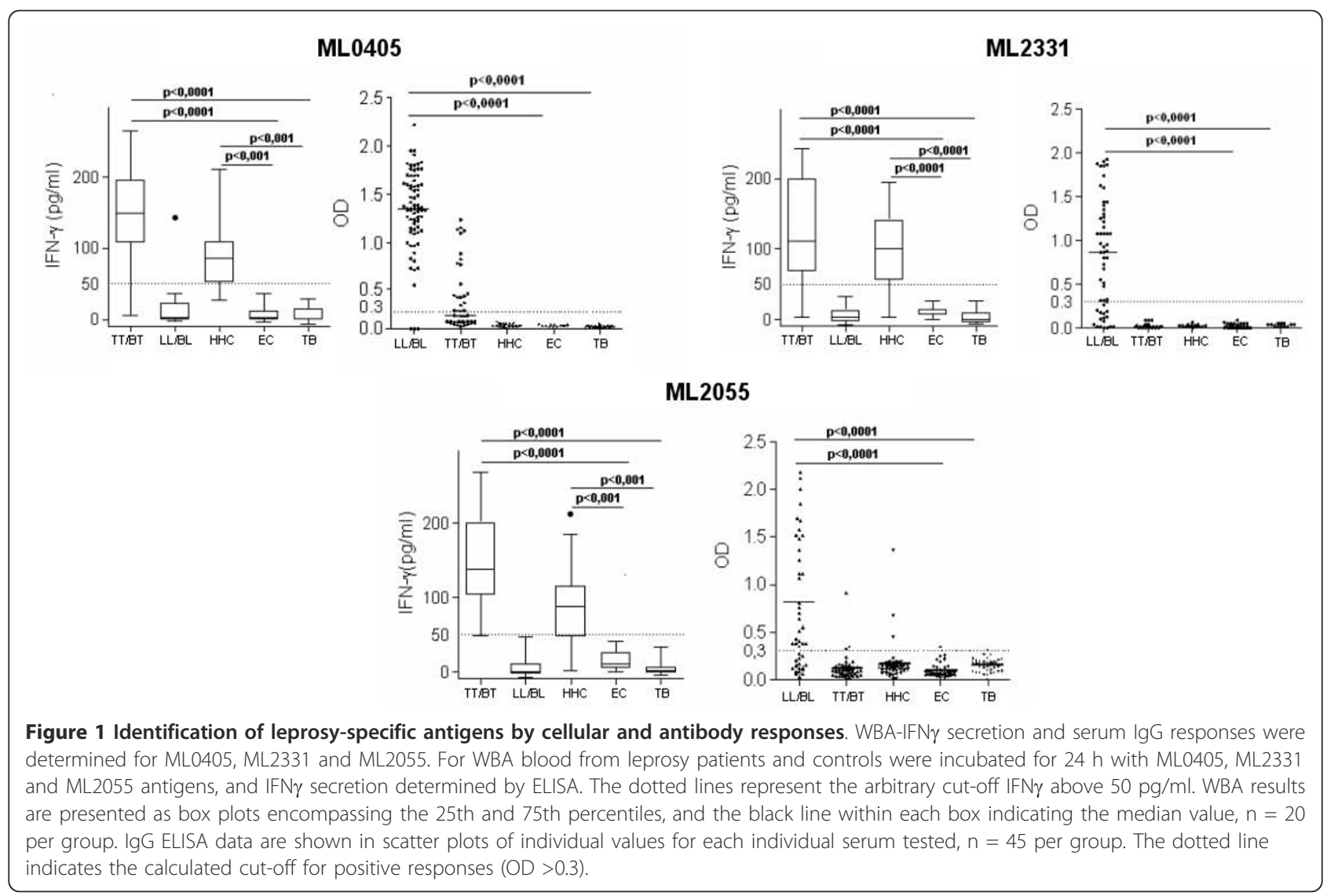


(Figure1) [3,28]. The ML2055 antigen demonstrated a strong serum antibody reactivity in the LL/BL patient group (median $\mathrm{OD}=1.43$; IQR $=1.26$ ) with $58 \%$ (26 of 45) sera binding above the positive threshold (OD $>0.3$; Figure 1). Antibody responses to ML0405, ML2055 and ML2331 within all other groups analyzed (TT/BT, HHC, TB and EC) were weak or absent. Taken together, the data indicate that ML0405, ML2055 and ML2331 are recognized specifically among leprosy patients and contacts, albeit differentially inducing either antibody or cellular responses.

\section{Antigens that stimulate leprosy-specific $\mathrm{CMI}$ without specific antibody responses}

Five proteins were found to elicit cellular responses despite not being detected by serum antibodies. In agreement with our previous findings, antigens ML0840 and ML2044 induced significantly greater IFN $\gamma$ secretion in WBA using blood from TT/BT leprosy patients than WBA using EC blood (Figure 2) [4]. These proteins did not, however, demonstrate significant antibody reactivity in any of the study groups (Figure 2). Among the TT/BT patients, IFN $\gamma$ production was induced by incubation with the ML1632 protein in 80\% (16 of 20) cases; by the ML1685 and ML1556 proteins in 75\% (15 of 20) cases. Antigen-specific IFN $\gamma$ responses were again induced in the HHC samples, with 65\% HHC (13 of 20) responding to the ML1632 and ML1685 proteins, and $25 \%$ HHC (5 of 20) responding to the ML1556 protein (Figure 2). Thus, our data identifies five M. leprae proteins (ML0840, ML2044, ML1632, ML1685 and ML1556) that, despite stimulating IFN $\gamma$ production in
WBA using blood from the TT/BT and HHC groups, are not detected by serum IgG responses of leprosy patients.

We previously demonstrated that the ML0276 protein induces IFN $\gamma$ secretion from TT/BT leprosy patient and HHC blood but not from controls [4]. When the ML0276 protein was used in ELISA to detect antibodies, strong serum IgG reactivity was observed in all study groups (Figure 3). Our data thereby indicate that although the cellular response to ML0276 is specific to leprosy groups, the anti-ML0276 antibody response lacks specificity. Medium values of IFN $\gamma$ produced in WBA and OD of ELISA tests to detect IgG to the immunogenic $M$. leprae recombinant proteins identified in this study, stratified by different study groups are shown in Additional File 2.

\section{Non-specific cellular responses are observed against many proteins}

In contrast with the leprosy-specific cellular responses of the proteins categorized above, several of the recombinant proteins tested, in addition to the TT/BT leprosy group, stimulated IFN $\gamma$ release in the TB or EC groups (ML0022, ML2358, ML2346, ML2380, ML2541, ML2603 and ML2203) (Figure 4). Of note, the LL/BL leprosy group did not respond to these proteins. The number of responders to each of these proteins, and the magnitude of the response, were generally also much lower than those observed for the proteins that were specifically recognized by TT/BT leprosy group. Despite the presence of cellular responses, these proteins did not demonstrate IgG reactivity.

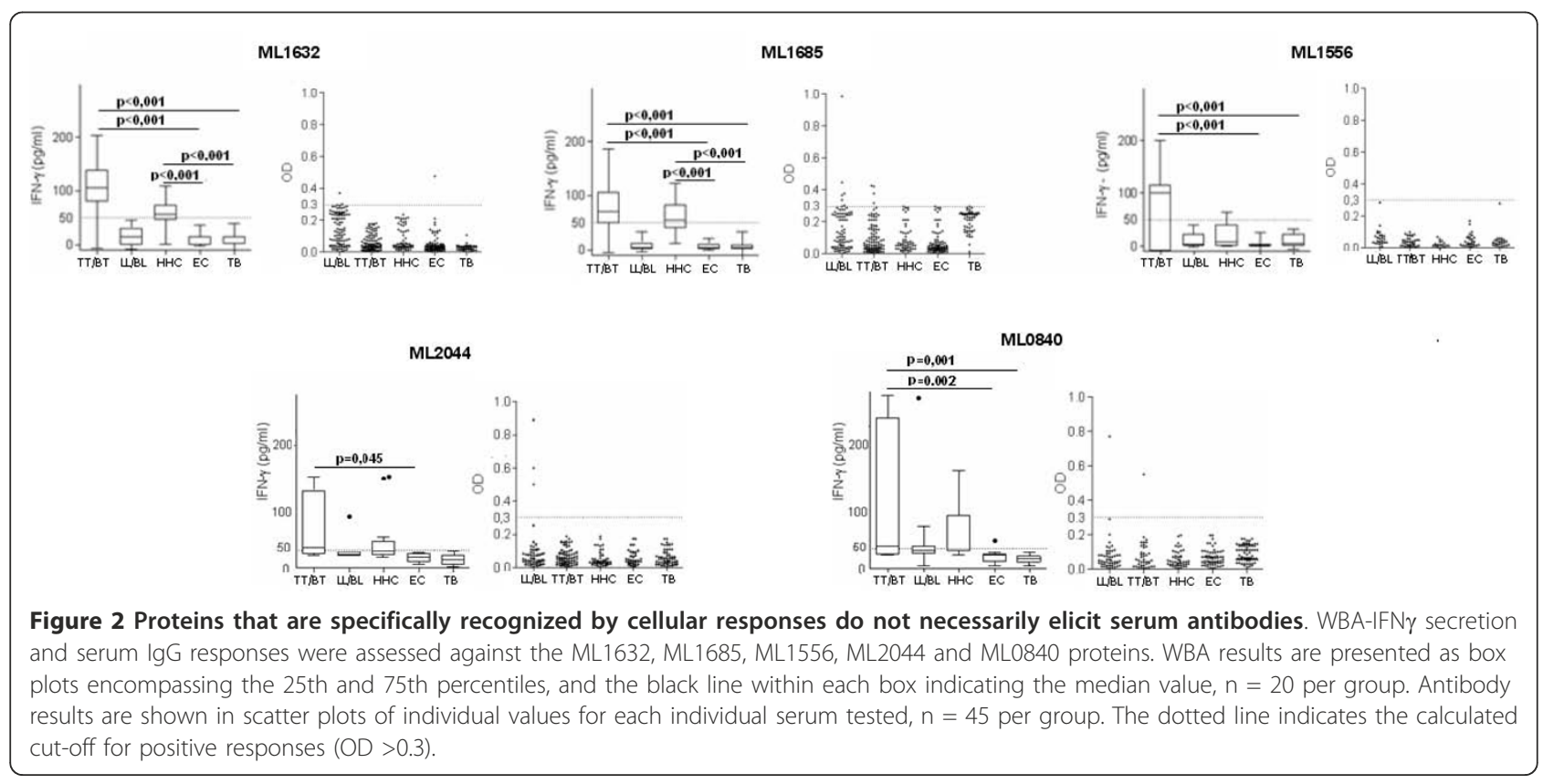



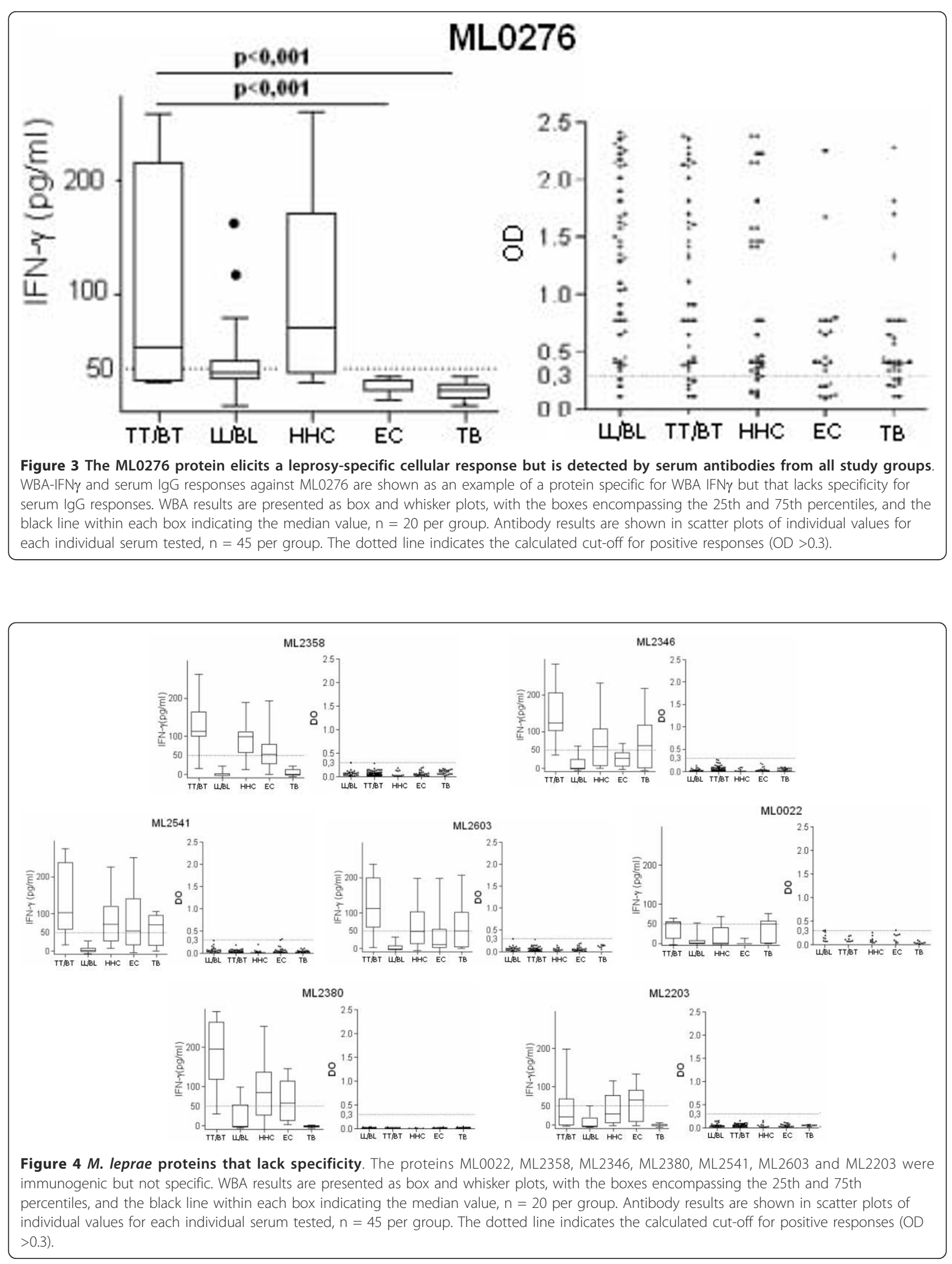
In silico predictions of immune reactivity and specificity are poor

Comparative analyses of amino acid sequences of the $M$. leprae proteins evaluated immunologically were conducted against the predicted proteomes of $M$. tuberculosis, M. avium, M. marinum, M. ulcerans, M. bovis BCG (Table 2), M. smegmatis, M. paratuberculosis and $M$. microti (Additional File 3). Only the ML2346 protein could be considered $M$. leprae unique, with no homologues found in the other mycobacteria species examined (Table 2). The other $M$. leprae proteins tested herein possessed an ortholog protein in other pathogenic mycobacteria, with homology ranging from $29 \%$ to $97 \%$ (Table 2 and Additional File 3). This high homology was not, however, associated with a lack of specificity in ex vivo assays. For example, the ML2331 protein possesses $81 \%$ homology with the Rv3717 ortholog in $M$. tuberculosis, but this protein was not reactive with TB patient samples and responses against ML2331 could only be demonstrated in leprosy patients (or HHC). Thus, despite possessing significant levels of homology with other mycobacteria species, several $M$. leprae proteins are only recognized in the context of leprosy.

Having found widely discrepant levels of reactivity in our immune assays, we retrospectively compared our results with in silico predictions to determine if computational analyses could have streamlined the in vivo assays. In general, the number of predicted $\mathrm{B}$ cell and $\mathrm{T}$ cell epitopes was directly proportional to the size of the protein (Table 2). In silico predictions indicated that each of the proteins tested contained up to seven promiscuous $\mathrm{T}$ cell epitopes, indicating that all had the potential to be reactive in WBA (Table 2). This prediction clearly contradicts our observation that more than half of the antigens tested (ML0051, ML0098, ML2028, ML0176, ML1633, ML0393, ML0489, ML2655, ML0491, ML0540, ML0810, ML1383, ML1481, ML2629, ML2659, ML0811 and ML1181) neither induced IFN $\gamma$ secretion nor showed IgG reactivity (Figure 5). The in silico predictions of HLA binding regions within an antigen sequence do not predict interactions with the $\mathrm{T}$ cell receptor (TCR). The analyses employed herein were poor to determine the proteins that are targets of the adaptive immune response of leprosy patients.

\section{Discussion}

Early and accurate diagnosis of leprosy and MDT are considered essential to disrupt $M$. leprae transmission and leprosy incidence. Due to the complex and varying immune responses that characterize leprosy spectrum, it is likely that immune diagnosis will only be achieved by antigens that specifically induce cellular and humoral responses $[8,19]$. Identifying antigens that are targets of the proinflammatory $\mathrm{T}$ cell response could also reveal those that are associated with limiting $M$. leprae burden and therefore useful for vaccination. In this study a panel of recombinant $M$. leprae proteins was evaluated for the ability to induce CMI and antibody responses to identify antigens that are specifically reactive in leprosy patients. Although many antigens were identified as cellular targets by their ability to induce IFN $\gamma$ secretion in WBA of TT/BT leprosy patients and HHC, a minority of the screened proteins induced serum IgG responses in BL/LL patients, such that few proteins induced specific responses across the leprosy spectrum.

In silico analysis predicted the presence of $\mathrm{T}$ cell and B cell epitopes within all of the M. leprae proteins tested in this study. The most promiscuous $\mathrm{T}$ cell epitope predicted was located in ML0405 protein, which was estimated to contain $\mathrm{T}$ cell epitopes recognized by 50 of 51 of HLA-DR alleles along with 24 potential B cell epitopes. Consistent with this prediction, the ML0405 protein was recognized by IFN $\gamma$ release in WBA using TT/ BT leprosy patient blood and by serum IgG from LL/BL leprosy patients. However, despite the prediction that all of the evaluated proteins would possess multiple HLADR epitopes, more than half (17 of $33 ; 52 \%)$ of the proteins were not recognized by leprosy patients or controls. Our results are in agreement with previous studies that found some of these proteins were not immunogenic $[4,9,19-25]$. Although we cannot exclude the possibility that the proteins investigated were not recognized because individuals with the appropriate HLA were not recruited, we consider this improbable given the large degree of promiscuity that was predicted. Several other possibilities could explain the lack of reactivity. Although we consider it unlikely given the recognition of positive responses to many proteins, the simplest explanation would be that recombinant expression in E. coli leads to significantly different folding and processing of proteins than occurs during native expression in M. leprae. A more likely possibility is that these proteins, although present in the genome of M. leprae, may not be translated [16]. Another explanation could be that limited antigen-presentation or $\mathrm{T}$ cell suppression may occur during leprosy in order to prevent nerve damage via $\mathrm{T}$ cell-mediated killing of $M$. leprae-infected Schwann cells. We are aware that the softwares employed in this study identify and predict HLA binding regions from antigen sequences without predicting interactions with the TCR. Therefore the use of other in silico prediction softwares that also include the probability of the antigen being processed, presented in the context of a certain HLA allele and recognized by TCR could lead to different conlusions.

In leprosy endemic regions the high rates of concomitant exposure to $M$. tuberculosis and to other non-pathogenic environmental mycobacteria could confound the 


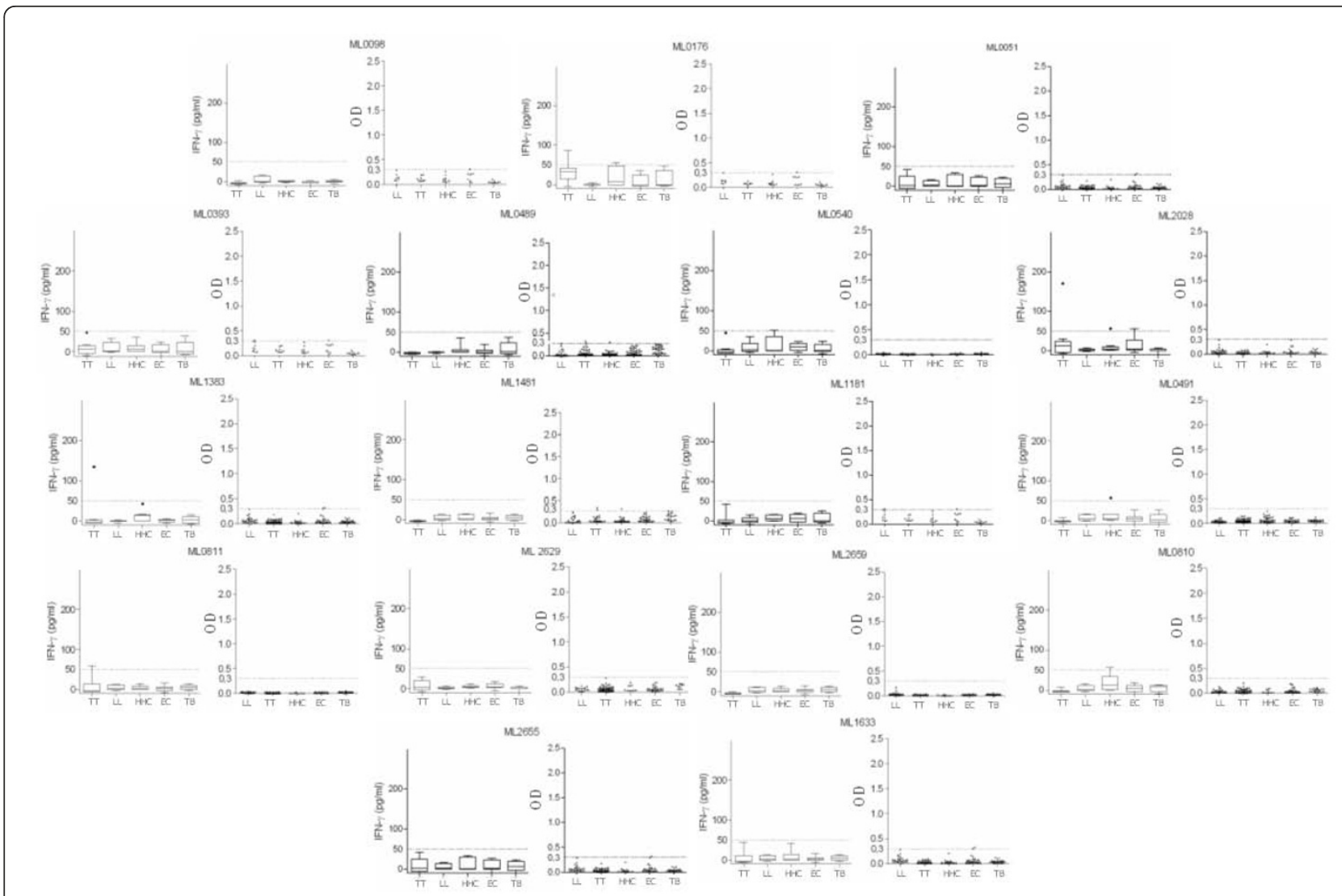

Figure $5 \mathrm{M}$. leprae proteins that are not reactive in WBA or antibody ELISA. WBA-IFN $\gamma$ secretion and serum IgG responses were assessed against the proteins ML0051, ML0098, ML2028, ML0176, ML1633, ML0393, ML0489, ML2655, ML0491, ML0540, ML0810, ML1383, ML1481, ML2629, ML2659, ML0811 and ML1181. WBA results are presented as box and whisker plots, with the boxes encompassing the 25th and 75th percentiles, and the black line within each box indicating the median value, $n=20$ per group. Antibody results are shown in scatter plots of individual values for each individual serum tested, $n=45$ per group. The dotted line indicates the calculated cut-off for positive responses (OD $>0.3)$.

determination of $M$. leprae-specific immune responses. Several of the $M$. leprae antigens tested in this study have homologues in other mycobacteria with greater than $50 \%$ identity (Table 1 ). The routine $M$. bovis BCG vaccination of newborns in leprosy-endemic countries such as Brazil could stimulate responses that could cross-react with $M$. leprae. M. bovis BCG showed high homology with immunogenic M. leprae proteins (from 62 to 88\%) This high homology was not, however, associated with neither cross -reactivity nor with a lack of specificity. For example, the ML2331 protein possesses over $80 \%$ identity with $M$. tuberculosis and M. bovis BCG proteins but serological and cellular responses to this antigen were highly specific to leprosy patients (or at-risk contacts). Antigen expression levels and bioavailability may determine the immune dominant antigens of each mycobacterial infection, such that differing responses to similar proteins may distinguish each disease. As a further demonstration of the limited ability of in silico predictions to indicate specificity, despite having no identified homologue in M. tuberculosis, the ML2346 protein induced strong IFN $\gamma$ responses in all of the study groups, including TB patients. Based on these findings we suggest that, at present, in silico identification of $M$. leprae proteins with high identity to other mycobacterial proteins should not be used as a definitive criterion to exclude them from further diagnostic or vaccine evaluations.

Several studies have reported antigen-specific cellular and antibody responses during leprosy, but few studies have consolidated data to determine if particular antigens are differentially recognized across the disease spectrum [3,4,9,19-25]. Araoz et al. described $M$. leprae recombinant proteins recognized by antibodies produced by lepromatous patients that that could also induce CMI among tuberculoid patients [19]. Some of the proteins analyzed in our study (ML1632, ML1685 and ML1556) induced strong and specific production of IFN $\gamma$ in TT/BT and HHC groups, demonstrating their potential application for identification of those at risk of developing tuberculoid leprosy. These proteins were not, however, recognized by antibodies from LL/BL patients. Our parallel screening suggested 
that the antibody response to $M$. leprae recombinant proteins was dependent upon their ability to induce cellular responses, and indicates only a limited number of $M$. leprae antigens contained $\mathrm{T}$ cell and $\mathrm{B}$ cell epitopes that are immune reactive in the context of disease (ML0405, ML2055 and ML2331). These antigens could be considered priority diagnostic antigens. In order to optimize the screening of new $M$. leprae antigens for leprosy diagnosis, our data suggest that it may be beneficial to conduct WBA testing before serological assays. If the protein is not able to induce a $\mathrm{T}$ cell response it could be de-prioritized from further testing.

\section{Conclusions}

In summary, our results identify new $M$. leprae antigens that are recognized by antibody responses of lepromatous patients and cellular responses of tuberculoid leprosy patients. The identification of IgG-reactive antigens indicates the possibility of developing an improved serological diagnostic test for leprosy, especially if these antigens can be incorporated to supplement the current PGL-I based tests $[10,11]$. For the diagnosis of tuberculoid leprosy, our data indicate the WBA is a robust, relatively simple and user friendly format with which to screen and identify new diagnostic antigens. Together, these test formats would be desirable for field use in leprosy endemic countries and could contribute to the active detection of leprosy cases before the development of deformities and disabilities.

\section{Additional material}

Additional file 1: IFN $\gamma$ production in WBA upon stimulation with PHA, MLCwA and PBS. This figure indicates IFN $\gamma$ production upon stimulation with positive controls (PHA and MLCWA) and the baseline concentration without any stimulant (PBS alone) used as negative control.

Additional file 2: IFN $\gamma$ produced in WBA and OD of ELISA tests to detect IgG to Immunogenic $M$. leprae recombinant proteins. The medium values of IFN $\gamma$ and IgG ELISA optical density (OD) are shown in all study groups.

Additional file 3: Percentage of amino acid identity of immunogenic $M$. leprae proteins with proteins from other relevant mycobacteria species. Blast Search for amino acid identity was performed using BLAST Uniprot (http://www.uniprot.org/). (-) = no homologue found. Locus_tag orthologous genes are indicated within parentheses.

\section{List of abbreviations}

BL: borderline lepromatous leprosy; BT: borderline tuberculoid leprosy; EC: endemic control; HHC: healthy household contact; IQR: interquartile range; LL: lepromatous leprosy; MB: multibacillary leprosy; MDT: multi-drug therapy; PB: paucibacillary leprosy; TB: tuberculosis; TT: tuberculoid leprosy; PGL-I: M. leprae cell wall phenolic glycolipid l; TCR: T cell receptor.

\section{Acknowledgements}

The researchers are members of the IDEAL (Initiative for Diagnostic and Epidemiological Assays for Leprosy) Consortium. This work was conducted with support from the American Leprosy Missions, The Heiser Program for Research in Leprosy and Tuberculosis of The New York Community Trust and UNICEF/UNDP/World BankWHO Special Programme for Research and Training in Tropical Diseases (TDR). Sampaio LH and Oliveira RM were supported by scholarships from CAPES (Brazil) and CNPq/National Counsel of Technological and Scientific Development (Brazil); Stefani MM is the recipient of a fellowship from CNPq (grant\#304869/2008-2). We are grateful to the patients and staff of the Reference Center for Diagnosis and Treatment in Goiânia/Goiás for their cooperation and support.

\section{Author details}

${ }^{1}$ Tropical Pathology and Public Health Institute, Federal University of Goiás, Rua 235 esquina com 1a Avenida, Setor Universitário, sala 335, Goiânia, GO, 74605050, Brazil. ${ }^{2}$ Infectious Disease Research Institute, 1124 Columbia St, Suite 400, Seattle, WA 98104, USA.

\section{Authors' contributions}

LHS recruited patients, performed the experiments, analyzed the data and wrote the paper. MMAS conceived and designed the experiments, coordinated the field work, performed the experiments, analyzed the data, contributed reagents/materials/analysis tools and wrote the paper. RMO performed the experiments. ALMS recruited patients and performed the experiments. GCl performed the experiments and contributed reagents/ materials/analysis tools. SGR performed the experiments, analyzed the data and contributed reagents/materials/analysis tools. MSD performed the experiments, analyzed the data, contributed reagents/materials/analysis tools and wrote the paper. All authors read and approved the final manuscript.

\section{Competing interests}

The authors declare that they have no competing interests.

Received: 17 September 2010 Accepted: 26 January 2011

Published: 26 January 2011

\section{References}

1. WHO: Global leprosy situation, 2010. Wkly Epidemiol Rec 2009, 85:337-348.

2. Scollard DM: The biology of nerve injury in leprosy. Lepr Rev 2008, 79:242-253.

3. Duthie MS, Goto W, Ireton GC, Reece ST, Cardoso LP, Martelli CM, et al: Use of protein antigens for early serological diagnosis of leprosy. Clin Vaccine Immunol 2007, 14:1400-1408.

4. Duthie MS, Goto W, Ireton GC, Reece ST, Sampaio LH, Grassi AB, et al: Antigen-specific T-cell responses of leprosy patients. Clin Vaccine Immunol 2008, 15:1659-1665.

5. Yamamura M, Uyemura K, Deans RJ, Weinberg K, Rea TH, Bloom BR, et al: Defining protective responses to pathogens: cytokine profiles in leprosy lesions. Science 1991, 254:277-279.

6. Scollard DM, Adams LB, Gillis TP, Krahenbuhl JL, Truman RW, Williams DL: The continuing challenges of leprosy. Clin Microbiol Rev 2006, 19:338-381.

7. Lockwood DN, Suneetha S: Leprosy: too complex a disease for a simple elimination paradigm. Bull World Health Organ 2005, 83:230-235.

8. Aseffa A, Brennan P, Dockrell H, Gillis T, Hussain R, Oskam L, et al: Report on the first meeting of the IDEAL (Initiative for Diagnostic and Epidemiological Assays for Leprosy) consortium held at Armauer Hansen Research Institute, ALERT, Addis Ababa, Ethiopia on 24-27 October 2004. Lepr Rev 2005, 76:147-159.

9. Geluk A, van der Ploeg-van Schip JJ, van Meijgaarden KE, Commandeur S, Drijfhout JW, Benckhuijsen WE, et al: Enhancing sensitivity of detection of immune responses to Mycobacterium leprae peptides in whole-blood assays. Clin Vaccine Immunol 2010, 17:993-1004.

10. Buhrer-Sekula S, Smits HL, Gussenhoven GC, van Leeuwen J, Amador S, Fujiwara T, et al: Simple and fast lateral flow test for classification of leprosy patients and identification of contacts with high risk of developing leprosy. J Clin Microbiol 2003, 41:1991-1995.

11. Buhrer-Sekula S, Illarramendi X, Teles RB, Penna ML, Nery JA, Sales AM, et al: The additional benefit of the ML Flow test to classify leprosy patients. Acta Trop 2009, 111:172-176.

12. Stefani MM: Challenges in the post genomic era for the development of tests for leprosy diagnosis. Rev Soc Bras Med Trop 2008, 41(Suppl 2):89-94.

13. Imtech: PROPRED. [http://www.imtech.res.in/raghava/propred/]. 
14. SANGER CDS Retrieve Information: Sanger Institute.[http://www.sanger.ac uk/Projects/M_leprae/].

15. The Universal Protein Resource: Uniprot. [http://www.uniprot.org/ taxonomy/362242].

16. Institut Pasteur: Leproma. [http://genolist.pasteur.fr/Leproma/].

17. Imtech: ABCpred. [http://www.imtech.res.in/raghava/abcpred/ ABC_submission.html].

18. Cole ST, Eiglmeier K, Parkhill J, James KD, Thomson NR, Wheeler PR, et al: Massive gene decay in the leprosy bacillus. Nature 2001, 409:1007-1011.

19. Araoz R, Honore N, Cho S, Kim JP, Cho SN, Monot M, et al: Antigen discovery: a postgenomic approach to leprosy diagnosis. Infect Immun 2006, 74:175-182.

20. Araoz R, Honore N, Banu S, Demangel C, Cissoko Y, Arama C, et al: Towards an immunodiagnostic test for leprosy. Microbes Infect 2006, 8:2270-2276.

21. Dockrell HM, Brahmbhatt S, Robertson BD, Britton S, Fruth U, Gebre N, et al: A postgenomic approach to identification of Mycobacterium lepraespecific peptides as T-cell reagents. Infect Immun 2000, 68:5846-5855.

22. Geluk A, Klein MR, Franken $K L$, van Meijgaarden KE, Wieles B, Pereira KC, et al: Postgenomic approach to identify novel Mycobacterium leprae antigens with potential to improve immunodiagnosis of infection. Infect Immun 2005, 73:5636-5644.

23. Geluk A, Ottenhoff TH: HLA and leprosy in the pre and postgenomic eras. Hum Immunol 2006, 67:439-445.

24. Geluk A, van der PJ, Teles RO, Franken KL, Prins C, Drijfhout JW, et al: Rational combination of peptides derived from different Mycobacterium leprae proteins improves sensitivity for immunodiagnosis of $\mathrm{M}$. leprae infection. Clin Vaccine Immunol 2008, 15:522-533.

25. Geluk A, Spencer JS, Bobosha K, Pessolani MC, Pereira GM, Banu S, et al: From genome-based in silico predictions to ex vivo verification of leprosy diagnosis. Clin Vaccine Immunol 2009, 16:352-359.

26. Spencer JS, Dockrell HM, Kim HJ, Marques MA, Williams DL, Martins MV, et al: Identification of specific proteins and peptides in mycobacterium leprae suitable for the selective diagnosis of leprosy. J Immunol 2005, 175:7930-7938.

27. Ridley DS, Jopling WH: Classification of leprosy according to immunity. A five-group system. Int J Lepr Other Mycobact Dis 1966, 34:255-273.

28. Reece ST, Ireton G, Mohamath R, Guderian J, Goto W, Gelber R, et al: ML0405 and ML2331 are antigens of Mycobacterium leprae with potential for diagnosis of leprosy. Clin Vaccine Immunol 2006, 13:333-340.

29. Jain E, Bairoch A, Duvaud S, Phan I, Redaschi N, Suzek BE, et al: Infrastructure for the life sciences: design and implementation of the UniProt website. BMC Bioinformatics 2009, 10:136.

30. Singh H, Raghava GP: ProPred1: prediction of promiscuous MHC Class-I binding sites. Bioinformatics 2003, 19:1009-1014.

31. Saha S, Raghava GP: Prediction of continuous B-cell epitopes in an antigen using recurrent neural network. Proteins 2006, 65:40-48.

\section{Pre-publication history}

The pre-publication history for this paper can be accessed here:

http://www.biomedcentral.com/1471-2334/11/26/prepub

doi:10.1186/1471-2334-11-26

Cite this article as: Sampaio et al:: Immunologically reactive $M$. leprae antigens with relevance to diagnosis and vaccine development. $B M C$ Infectious Diseases 2011 11:26.

\section{Submit your next manuscript to BioMed Central and take full advantage of:}

- Convenient online submission

- Thorough peer review

- No space constraints or color figure charges

- Immediate publication on acceptance

- Inclusion in PubMed, CAS, Scopus and Google Scholar

- Research which is freely available for redistribution 